\title{
Lived experiences of self-care among older physically active urban-living individuals
}

This article was published in the following Dove Press journal:

Clinical Interventions in Aging

29 January 2013

Number of times this article has been viewed

\section{Kari Sundsli ${ }^{1,2}$ \\ Geir Arild Espnes ${ }^{3}$ \\ Olle Söderhamn ${ }^{2}$}

'Department of Social Work and Health Science, Faculty of Social Sciences and Technology Management, NTNU, Trondheim, Norway, ${ }^{2}$ Centre for Caring Research, Southern Norway, Faculty of Health and Sport Sciences, University of Agder, Grimstad, Norway, ${ }^{3}$ Research Centre for Health Promotion and Resources HiST-NTNU, Department of Social Work and Health Science, Faculty of Social Sciences and Technology Management, NTNU, Trondheim, Norway
Correspondence: Kari Sundsli Centre for Caring Research, Southern Norway, Faculty of Health and Sport Sciences, University of Agder, PO Box 509, NO-4898

Grimstad, Norway

Tel +473723 3784

Email kari.sundsli@uia.no
Background: Promoting physical activity is a public health priority in most industrial countries, and physical function is an important factor when taking into consideration older people's self-care and health. Despite the increasing challenges associated with urbanization and the aging population, urban life appears to be positive in many ways for urban dwellers. However, the manner in which older people live in urban settings and how this influences their ability to take care of themselves should be considered important knowledge for health professionals and politicians to acquire. The aim of this study was to describe the lived experiences of selfcare and features that may influence health and self-care among older urban home-dwelling individuals who are physically active.

Methods: Ten subjects, three women and seven men, who were aged 65-82 years and identified to be physically active, were interviewed. The interviews were recorded, transcribed verbatim, and analyzed according to the descriptive phenomenological method devised by Giorgi.

Results: Our findings showed beneficial self-care. The participants lived active everyday lives and were frequently physically active. They were part of a supportive, inclusive, and promoting fellowship, and they had the opportunity to travel. They utilized their competence and experienced making themselves useful. It was a privilege to be part of a family life as a husband, wife, parent, and/or a grandparent. They acknowledged physical and mental limitations, yet they felt they were in good health.

Conclusion: Health professionals and politicians should identify places where fellowship and relationships can be built, as well as encourage older people to use their competence by engagement in volunteering. These interventions are important to support older people's self-care and health. This may also be a way to reduce ageism in Western societies.

Keywords: aged, health promotion, perceived health, phenomenology

\section{Introduction}

Self-care may be viewed as a goal-directed activity with the aim of maintaining, restoring, or improving health and well-being. ${ }^{1}$ Other aspects of self-care are health maintenance, disease prevention, detection, management, treatment, and health promotion. ${ }^{2}$ Health promotion has been internationally recognized as a key factor in achieving active ageing. ${ }^{3}$ It is the process of enabling people to increase control over and improve their health, thereby enabling them to lead an active, productive life towards good well-being and quality of life. ${ }^{4}$ Special focuses within health promotion are problem-solving, enabling people to move in the direction of health, and a global and pervasive sense in individuals, groups, populations, or systems that serves as the capacity for healthpromoting processes. ${ }^{3}$ Vulnerable persons with impaired physical function, as is the case 
with many older individuals, are likely to have difficulties in maintaining their potential for self-care sufficiently to enjoy good health. ${ }^{1}$ It has been shown that conditioning factors ${ }^{5}$ such as receiving help, perceived helplessness, and age may influence the amount of therapeutic self-care demands among older people. ${ }^{6}$ Perceived influences on the body are important, and the individual should (alone or with support from another individual) be able to bring about a change in attitude towards his or her personal lifestyle or life situation ${ }^{7}$ in order to be considered as possessing a sufficient degree of self-care ability. The meaning of actualizing self-care ability among older home-dwelling people has been interpreted as self-realization or self-transcendence. Therefore, it should be important for formal and informal caregivers, as well as relatives and friends to support the actualization of older people's resources in order to make it possible for this expanding group in society to obtain health and well-being. ${ }^{8}$ However, little is known about the meaning of these healthrelated resources and their actualization.

Understanding older people's health and what makes them continue to live good lives are some of the main issues concerning older people living in their own homes. ${ }^{8,9}$ The World Health Organization has declared that health is a state of complete physical, mental, and social well-being and not merely the absence of disease or infirmity. ${ }^{10}$ Moreover, health is understood as a position on a health ease/dis-ease continuum, moving towards the healthy end. ${ }^{4,11}$ In most industrial countries, physical activity is a public health priority, and it is well documented that a physically active lifestyle reduces the risk of developing cardiovascular disease, diabetes, obesity, osteoporosis, several forms of cancer, and depression. ${ }^{12,13}$ According to Chen et al, ${ }^{14}$ physical function is one of the most important predictors of health in older people. Older people, who perceive themselves as being in good health may not think that physical activity is necessarily for them unless they acknowledge or believe in the health benefits to be gained from physical activity. ${ }^{15,16}$ In this study, health is described as an ongoing process in which individuals interact with the environment throughout their entire life span, and that people's life orientation has an impact on health.

Urbanization and the aging population are some of the greatest challenges at the present time and will increase in coming decades. ${ }^{17}$ Various studies reflect the statement that urban life seems to be a good life on the whole, despite the challenges caused by urbanization. ${ }^{18-20}$ Older urban people report higher self-esteem, increased positive mood, better emotional health, and more satisfaction with aging, as well as better functional health status and a higher degree of physical function and mental health than do their counterparts living in rural areas. ${ }^{20-22}$

European countries are currently undergoing significant changes in their demographic and epidemiological development. One of these changes is the increasing number of citizens aged 67 years or more, a number expected to double by $2050 .{ }^{17}$ This is also the case in Norway, because $11 \%$ of the population in the four largest cities is currently older than 67 years, and life expectancy has increased by ten years for both women and men. ${ }^{23}$ Results from a recent quantitative study of older urban people aged $65+$ years in southern Norway showed that a majority perceived themselves as being in good health, felt satisfied with their lives, and perceived themselves as being active. However, 10.6\% perceived themselves as being helpless and $11.1 \%$ perceived themselves as being anxious. ${ }^{8}$ While these results are positive, life expectancy in Norway seems to lag behind that of other European countries. ${ }^{24}$ Living in cities might enable human collaboration in the sense that people learn from other people. Perhaps this occurs because the essential characteristic of humanity is our ability to learn from one another, and cities make us more human. ${ }^{20}$ Learning how people experience urban life and how this life influences their health and ability to take care of themselves should be of utmost importance for both health professionals and politicians, as well as researchers in the years to come.

The aim of this study was to describe the lived experiences of self-care and features that may influence health and self-care among urban older home-dwelling individuals who are physically active.

\section{Materials and methods}

This study used the descriptive phenomenological methodology devised by Giorgi ${ }^{25}$ to analyze narrated lived experiences of self-care and features that may influence health and self-care among older home-dwelling individuals who are physically active.

\section{Study group}

The participants were recruited from home-dwelling older people living in urban areas in southern Norway. Ten persons $65+$ years of age, who had already participated in a survey in southern Norway ${ }^{8}$ during the spring of 2010 and found to be physically active on a daily basis $(n=636)$ were asked to participate in an interview concerning their perceptions of self-care in relation to physical activities. Ten women and ten men were selected by drawing lots, and a letter with information about the study and a request for participation 
was sent to them by mail. Six persons wanted to participate, and after one reminder another four persons agreed to participate by sending back a signed sheet that was considered to be informed consent. All these persons were contacted by telephone, and appointments were arranged. The sample comprised three women and seven men aged 65-82 years. Three participants lived alone (two widows/widowers, one divorcee), while the rest lived with their spouses.

\section{Interviews}

All of the interviews were undertaken in the homes of the participants during the autumn of 2010 and spring 2011. An open-ended question was formulated in order to let the participants speak freely about experiences of physical activity concerning self-care. The opening question was as follows: "Please tell me about a situation you have experienced where physical activity was important to maintain health and wellbeing and where physical activity was important to manage your daily life and your self-care." To elaborate on a subject, the question: "Could you please tell me more about that?" was used. The interviews lasted 30-60 minutes and were recorded and transcribed verbatim.

\section{Data analysis}

The interviews were analyzed according to Giorgi's descriptive, phenomenological method. ${ }^{25}$ The transcript of each interview was read closely to get an overall sense of what the transcription was about (step 1). After this reading, the transcription was read again more slowly with a phenomenological attitude and mindful of the fact that the transcription purports to be an experience of health and self-care when being physically active (step 2). Every time a shift of meaning in the transcription was noticed, a mark was made in the transcription. The end result of this process was that the whole transcript was broken into parts called meaning units.

In the third step, ${ }^{24}$ each meaning unit was first repeated with the same words except for a change from first-person expression into third-person expression (step 3). The meaning units were then transformed from everyday language into the language of health science. At the end of the third step, a series of transformed meaning units was revealed. These were marked with different colors and formed the basis for the writing of the situated structure for each interview, which was essential for the phenomenon to manifest itself.

Step four contains both the formulation of a situated structure and a general structure. According to Giorgi, ${ }^{25}$ the situated structure has to be mindful of the whole, bringing a holistic perspective to the meaning units trying to determine the key constituents of the structure, as well as removing the key ones in order to see if the phenomenon stands or collapses. The ten situated structures, one for each interview, contributed to the general structure, which brings about the essence of the self-care experienced and features that may influence health and self-care in individuals who are physically active. The general structure and the features which the general structure is based on are presented in the Results section.

\section{Ethics approval}

The study was designed and implemented according to the Declaration of Helsinki ${ }^{26}$ and the principles commonly used in clinical research. ${ }^{26,27}$ The Regional Committee for Medical Research Ethics in southern Norway approved the study (REK Sør-Øst A 2009/1321). The participants were informed about the study in writing and guaranteed anonymity and confidentiality. Return of a signed agreement was considered to be informed consent to participate in the study.

\section{Results \\ General structure}

Self-care as a lived experience among older home-dwelling individuals living in urban areas who were physically active was narrated as follows. The participants lived active everyday lives and were frequently physically active. They were part of a supportive, inclusive, and promoting fellowship, and had the opportunity to travel. They utilized their competence and experienced making themselves useful. It was a privilege to be part of family life as a husband, wife, parent, and/or grandparent. They acknowledged physical and mental limitations, yet they felt they were in good health.

\section{Features influencing health and self-care in older physically active home-dwellers} Active everyday life and physical activity

The participants reported that having a daily routine gave meaning to their everyday lives. After breakfast and reading the morning newspaper, there was work waiting for them to organize, a friend waiting for their daily walk, or a piece of work to be done for an organization. This was a good experience. Now having the time, compared with previously, to enjoy the garden, take a walk to the harbor, experience being in good health, and the opportunity to be physically active and attend different activities as a senior citizen, were good experiences in the participants' lives.

It was important to be physically active for as long as possible to improve and maintain health, because this might 
well influence their longevity. Physical activity was vital for experiencing a good life when dealing with the aging process. Living conditions influenced their opportunities to take care of themselves and the prospect of how long it was possible to live in their own homes.

Being physically active on a frequent basis enabled the participants to be involved and engage together with friends and family, and gave them the opportunity to help other people if necessary.

Physical activity had been important in childhood and adolescence, like growing up on a farm doing manual work or being active in different kinds of sport. Participants believed that it is easier to be active in older age if one has been accustomed to physical activity earlier in life.

The participants were physically active, walking, cycling, weight-training, skiing, sailing, hiking in the mountains, dancing, or working with logs. Being physically active is also a part of everyday life nowadays, eg, shoveling snow, carrying wood to the house, and doing different kinds of maintenance work, like house painting and carpentry. Working in the soil and gardening were also important activities which kept them in good physical shape so that they could meet their everyday challenges.

The experience of being physically active was accompanied by a feeling of joy at being in good shape when finding oneself in need of a walk. None of the participants wanted to sit back and do nothing. Instead, they wanted to be active, going for long walks, keeping up with home maintenance, and helping other people in their surroundings.

\section{Inclusive, supportive, and promoting fellowship}

It was important to be part of a fellowship that was inclusive and supportive, and also that it enabled people to promote their health and self-care. Important fellowships were, eg, groups where people, two or more, meet to go for a walk, play musical instruments, share everyday life with its joys and sorrows, dance, talk about local history, go to a concert or listen to a lecture, watch a movie, share their interests of old cars, doing handcraft, playing bridge, discussing politics, or sharing their religious faith. These groups were either informal groups with friends or more formal groups as part of local organizations.

\section{Opportunity to travel}

Being able and having the opportunity to travel abroad or within their own country were valued by the participants. It was fascinating to experience and get to know different cultures and other peoples' way of life, and made the participants grateful for what they had back home. Most of the participants travelled together with their partner or their whole family, and some did it on their own. Some of the participants did not travel anymore because they were alone, or had other reasons, even if they were used to travelling before.

\section{Utilizing competence and being useful}

To make oneself useful brought good feelings in the participants' lives. Being engaged in grandchildren's lives by helping with homework, listening to their stories, joining them in skiing and other sporting activities, being involved in voluntary work, such as helping older people with gardening and snow shoveling, or collecting equipment for schoolchildren who do not have, for example, skates or skis, was considered invaluable. Voluntary work within the community as a secretary for an association or as a member of a religious, political, or sports organization was considered an important assignment for the participants.

To utilize one's competence was another vital experience, which gave meaning to the participants' lives and a perception of being privileged. They had competence concerning carpentry, electricity, mechanics, textiles, or lumbering, and some of them still had their own businesses to take part in.

\section{Family life}

Being surrounded by children and grandchildren made the participants feel privileged and also brought forth feelings of joy and happiness. One of the participants believed that his wife was the reason for his good health. Another explained that their car brought good experiences of well-being for both him and his wife. Most of the participants lived with their spouses, which they found good.

\section{Physical and mental limitations and good health}

The participants acknowledged limitations concerning their physical and mental health. These limitations were, for example, reduced heart or lung function, hearing impairment, and impaired balance. Reduced physical function made the participants choose an easier walking route, more gentle exercise, or adjustment of their speed according to their physical capacity.

Sickness in the family and loss of family members were challenges in the participants' lives. They could experience feelings of being exhausted, being in need of a rest, being alone, or grief as they mourned their loved ones. These changes in life provided opportunities for new friendships and personal development. 
The participants realized that they were getting older and reflected upon important moments in life which had passed by and would not come again, and what they did not like about getting old. Thoughts concerning the future that they have to tidy up and that their time is coming to an end influenced them. Despite their physical and mental limitations, the participants emphasized the importance of not resigning themselves to the end of life and remaining in the sofa. Instead, they recommended getting up and about. Being satisfied with oneself and enjoying the present was valued.

\section{Discussion}

The aim of this study was to describe the lived experiences of self-care and features that may influence health and selfcare among older urban home-dwelling individuals who are physically active. Philosophically, self-care ability can be explained by self-care activity and its goals, which are health and well-being. ${ }^{1}$ According to Moran, philosophy has been explained by Husserl as the description of what is given in direct evidence. ${ }^{28}$ In this sense, it should be possible to understand experiences of self-care in a Husserlian way, as a performance in which the experiencer experiences being as what it is. Furthermore, Husserl sums up the view that all experience is experience to someone, and is a "to whom" experience. This is what Husserl called "givenness", and in genuine phenomenological viewing we should attend only to the phenomena in the manner of their being given to us, in their modes of givenness. ${ }^{28}$ Being true to a genuine phenomenological perspective, one is not permitted to use any scientific or philosophical hypotheses. Instead phenomenology presents the concrete, lived human experience in all its richness. ${ }^{28}$

In this study, the descriptive phenomenology method of Giorgi ${ }^{25}$ was the researchers' guide to elucidating the phenomenon of self-care among older urban-living individuals who are physically active. Through bracketing and analyses, the essences of the narratives were revealed, and validity, in a phenomenological sense, was obtained. According to Husserl, ${ }^{29}$ being true to descriptive phenomenology requires that researchers are conscious of givenness, where no predisposition or interpretations are allowed to be brought forth. This does not mean that one should forget the past; instead, one should put aside all such temptations and systematically note and explore the ongoing occurrences as they are unfolding. Although this process seems impossible, the researchers have tried their best to analyze strictly according to the method, albeit with a principle of relevancy involved. Another important quality criterion is reliability, which was identified when the same meanings or acts in the narratives consistently appeared. ${ }^{30}$

The intention was that the lived human experiences of self-care in the study group have been presented in all their richness. The general structure of self-care as lived experiences obtained from older home-dwelling individuals living in urban areas who are physically active focused on the fact that the participants lived active everyday lives and were frequently physically active. They were part of a supportive, inclusive, and promoting fellowship and had the opportunity to travel. They utilized their competence and experienced making themselves useful. It was a privilege to be part of family life as a husband, wife, parent, and/or grandparent. They acknowledged physical and mental limitations, yet felt they were in good health.

The phenomenon of the research in this context was self-care. As mentioned, self-care can be viewed as a goaldirected activity with the aim to maintain, restore, or improve health and well-being. ${ }^{1,5}$ In this case, one can claim that the outcome of self-care is health and well-being, and according to Aristotle, one can understand self-care as the phenomenon being "work" (energeia) or "to live well"., 1,31 Self-care ability is the potential of what is possible for the person to achieve (goal), and self-care activity is what the person actually does. The participants lived active everyday lives and were physically active, which may point to the persons' potential for self-care. Most of the participants were accustomed to physical activity earlier in life, and this made sense in their lives as older people today. They believed that physical activity was vital for experiencing a good life when getting old and that it might also have an influence on their longevity. To be frequently physically active was a resource that made it possible to be involved and engaged together with friends and family, and was also an opportunity to help other people if needed. Physical activity was an important resource, which enabled the participants to keep up with domestic maintenance so that they could stay in their own homes for as long as possible. Other resources that had an impact on health and self-care were work waiting to be done, a friend waiting for a daily walk, and partaking in different activities. The fact that physical activity improves an individual's health and well-being is well documented. , $^{8,932-34}$ The participants' engagement in physical activity, which had been a part of their previous lifestyle, was now very important for these individuals.

In the descriptions of self-care performed by the participants, conditions of togetherness and relationships were revealed; throughout several life transitions, including 
marriage and divorce, sickness, death, aging, and retirement, the participants developed and established new relationships and fellowships. Arendt claims that it is in sheer human togetherness, where people meet people in a human relationship, that persons reveal their identities, and not by their emancipation from these relationships. ${ }^{31,35}$ None of the participants mentioned that they longed for solitude or preferred being alone. When describing their self-care and health, they would always return to situations and events which included other people. They described their experiences as being closely connected to other people's involvement in their lives, which would be as a husband, wife, children, friends, or colleagues. They also described the importance that these relationships had in their lives. Taking into account these findings and the fact that fellowship had a great influence on their health, it is clear that having opportunities to establish and maintain relationships is important for older people in order for them to manage in their everyday lives in their homes. ${ }^{18,36}$

Urban individuals seem to cope well in relation to health and self-care. ${ }^{8,19}$ Participants in the study group lived in urban areas where neighbors, friends, and relatives lived close by. They also lived close to city life, which offered different activities like shopping, going to the cinema, and to the sports center, clubhouse, or cafés. These opportunities made it easy to meet other people, even if one had physical difficulty, in getting around. Although they lived close to the city, the participants enjoyed the opportunities found in their natural surroundings, including taking walks in the woods on nicely paved footpaths, on the beaches, in parks, or around their neighborhoods. Identity of place as an important component of older people's self-identity is documented. ${ }^{37}$ The influence of the built environment in which the home is situated may increase or decrease the sense of well-being and participation in society. ${ }^{37,38}$ Urban life might offer city dwellers ample opportunities for both meeting other people and leaving their car behind and walking places instead, which in turn improves their capacity for self-care. . $^{80,39}$ Indeed, an individual's environment is important, because human existence and architectural space form a holistic entity in which human behavior may be described as a set of interrelated activities, settings, social interactions, and use of space. ${ }^{37}$ Older urban people are frequently physically active and use the range of facilities in their surroundings. ${ }^{8}$ Well planned physical environments might improve the older person's health. Architects and decision-makers have the opportunity in the next 5-10 years to initiate dialog with older people for the purpose of planning for a healthier and more active aging society. ${ }^{40}$
All the participants had committed their lives to someone else, which brought meaning into their existence and made their lives worth living. Children and grandchildren were highly appreciated and contributed to good feelings in their everyday life. Other things that were worth living for and investing energy in could be political work, being a member of a club, organizing important work in their local community, attending religious meetings and social gettogethers, participating in sports activities, utilizing their competence, feeling the joy of a well-toned body, enjoying the present, and being in overall good health. Despite having gone through difficult times in life, the participants had faced these challenges and done their best to overcome them. These experiences describe situations where the person is in relations to other acting beings and where he or she is never merely a "doer", but always and at the same time a sufferer, like opposite sides of the same coin. Arendt ${ }^{31}$ describes how these consequences become a chain reaction where every process is the cause of new processes, as a “... result of the bondless multitude of people involved ... because one deed, and sometimes one word, suffices to change every constellation". The participants experienced physical and mental limitations which to some extent made them suffer. They also experienced feelings of exhaustion, a need for rest, being alone, and mourning their loved ones. Simultaneously, they explained how they overcame these limitations. They explained how they thought, what they chose to do, and how they acted in order to experience health and self-care in their everyday lives. As they said, they did not want to resign themselves to remaining on the sofa. On the contrary, they recommended getting up and out, as well as being content within themselves and enjoying the present. There is an ongoing debate in society today about the coming decades and the growing number of people over the age of 65 years and the challenges population aging will bring about. Our study, in addition to the following recently published studies, reveals findings which might be essential and should be put into practice today.

A study on the transition into retirement and later life in a Nordic welfare context ${ }^{41}$ showed that the informants, aged 56-65 years of age, looked forward to retirement when they would be free and motivated to be active or even get a new job. In a study by Dale et al, ${ }^{9}$ the sense of being useful to other people is emphasized, as well as taking care of grandchildren. Being a volunteer was shown to be a major positive experience in a study on volunteering in dementia. ${ }^{42}$ The participants in that study reported that they performed well and expressed feelings of satisfaction. Furthermore, they experienced being seen, 
heard, and affirmed by staff as well as feeling life was more meaningful when they were doing meaningful things.

It is crucial to underline the fact that many people aged 65 years and over in Norwegian society have a high level of skills in many occupational areas. Health professionals, politicians, and health planners on every level should take the above findings into account when planning for the upcoming decades. Interventions like volunteering in a nursing home, or an activity center, or visiting older people living in their own homes, might bring forth positive experiences for all parties involved. ${ }^{43,44}$

\section{Conclusion}

In this study, older people who were physically active described their life situation as including good health and at the same time acknowledging their limitations, which are the opposite sides of the same coin. In other words, when returning to the self-care ability concept, the eidetic structure of ability for self-care in older home-dwelling people is twofold, ${ }^{1,7}$ and contains both being present to the opportunity to act on certain perceived influences on the body and, alone or with support from somebody else, to be able to bring about a change in attitude towards one's personal lifestyle or life situation. Our findings revealed descriptions of individuals who were willing to take on challenges in life and did their best to overcome them. They realized their potential in situations and acted using their resources, which might have contributed to their sense of self-realization in life today. While this is good for the individual, it also brings forth actualization of interventions at a societal level where health care planners from various fields, politicians, and older people themselves, are involved. Creating settings, where relationships and communities can be built should be a priority for both social and physical activities. Furthermore, there is a need for steps to be taken to promote, for example, volunteer work, where people can meet other people and their competences can be utilized in the best manner possible for older people living in institutions and those living in their own homes.

This study shows that being over 65 years of age and physically active in the 21 st century should be more appreciated by society. These individuals have the opportunity to participate and become involved in society's challenges and do important work on different levels in the years to come. They have valuable competence and knowledge that society needs, as well as engagement and involvement in their surroundings, all of which contribute to good health. Most importantly, this may be a way to reduce ageism in Western societies.

\section{Acknowledgments}

The study was carried out with the financial support of the Research Council of Norway (project number 187985) and the University of Agder. The informants are gratefully acknowledged, as well as Karin Beth Lee Hansen for the English language revision.

\section{Disclosure}

The authors report no conflicts of interest in this work.

\section{References}

1. Söderhamn O. Potential for self-care: assessing and describing selfcare ability among elderly people [Dissertation]. Linköping, Sweden: Department of Medicine and Care, Division of Nursing Science, Faculty of Health Sciences, Linköping: Linköpings Universitet;1998.

2. Lipson JG, Steiger NJ. Self-Care Nursing in a Multicultural Context. Thousand Oaks, CA: Sage Publications; 1996.

3. World Health Organization. Ottawa Charter for Health Promotion an International Conference on Health Promotion: the Move Towards a New Public Health. Ottawa, Canada: World Health Organization; 1986.

4. Eriksson M, Lindström B. Antonovsky's sense of coherence scale and its relation with quality of life: a systematic review. J Epidemiol Community Health. 2007;61(11):938-944.

5. Orem DE. Nursing: Concepts of Practice, 6th ed. St Louis, MO: Mosby Year Book; 2001.

6. Söderhamn O, Cliffordson C. The structure of self-care in a group of elderly people. Nurs Sci Q. 2001;14(1):55-58.

7. Söderhamn O. Self-care ability in a group of elderly Swedish people: a phenomenological study. J Adv Nurs. 1998;28(4):745-753.

8. Sundsli K, Söderhamn U, Espnes GA, Söderhamn O. Ability for selfcare in urban living older people in southern Norway. J Multidiscip Healthc. 2012;5:85-95.

9. Dale B, Söderhamn U, Söderhamn O. Life situation and identity among single older home-living people: a phenomenological-hermeneutic study. Int J Qual Stud Health Well-being. 2012;7:10.

10. World Health Organization. Constitution of the World Health Organization. Geneva, Switzerland: World Health Organization; 2007. Available from: http://apps.who.int/gb/bd/PDF/bd47/EN/ constitution-en.pdf. Accessed October 21, 2012.

11. Antonovsky A. Unraveling the Mystery of Health: How People Manage Stress and Stay Well. San Fransisco, CA: Jossey-Bass; 1987.

12. Shirley D, Van der Ploeg HP, Bauman AE. Physical activity promotion in the physical therapy setting: perspectives from practitioners and students. Phys Ther. 2010;90(9):1311-1322.

13. Windle G, Hughes D, Linck P, Russell I, Woods B. Is exercise effective in promoting mental well-being in older age? A systematic review. Aging Ment Health. 2010;14(6):652-669.

14. Chen KM, Hung HM, Lin HS, Haung HT, Yang YM. Development of the model of health for older adults. $J A d v$ Nurs. 2011;67(9):2015-2025.

15. Jancey JM, Clarke A, Howat P, Maycock B, Lee AH. Perceptions of physical activity by older adults: a qualitative study. Health Educ J. 2009;68(3):196-206.

16. Lindwall M, Rennemark M, Berggren T. Movement in mind: the relationship of exercise with cognitive status for older adults in the Swedish National Study on Aging and Care (SNAC). Aging Ment Health. 2008;12(2):212-220.

17. World Health Organization. Global age friendly cities: a guide. Geneva, Switzerland: World Health Organization; 2007. Available from: http://whqlibdoc.who.int/publications/2007/9789241547307_eng.pdf. Accessed February 28, 2011.

18. Nummela O, Sulander T, Karisto A, Uutela A. Self-rated health and social capital among aging people across the urban-rural dimension. Int J Behav Med. 2009;16(2):189-194. 
19. Vlahov D, Freudenberg N, Proietti F, et al. Urban as a determinant of health. J Urban Health. 2007;84(S1):16-26.

20. Glaeser EL. Triumph of the City. New York, NY: Penguin Press HC; 2011.

21. Lau R, Morse CA. Health and wellbeing of older people in AngloAustralian and Italian-Australian communities: a rural-urban comparison. Aust J Rural Health. 2008;16(1):5-11.

22. Chang SH. Beliefs about self-care among nursing home staff and residents in Taiwan. Geriatr Nurs. 2009;30(2):90-98.

23. Statistics Norway. Population statistics: Population and land area in urban settlements, as of January 1, 2012. Available from: http:// www.ssb.no/beftett/tab-2009-06-16-02.html and http://www.ssb.no/ folkemengde/. Accessed October 26, 2012.

24. Report No 25 (2005-2006) to the Storting. Long-term Care - Future Challenges. Oslo, Norway: Ministry of Health and Care Services; 2006.

25. Giorgi A. The Descriptive Phenomenological Method in Psychology: A Modified Husserlian Approach. Pittsburgh, PA: Duquesne University Press; 2009.

26. World Medical Association. WMA Declaration of Helsinki - ethical principles for medical research involving human subjects. Seoul, Korea: World Medical Association; 2008. Available from: http://www.wma. net/en/30publications/10policies/b3/index.html. Accessed Februrary 7, 2011.

27. Beauchamp TL, Childress JF. Principles of Biomedical Ethics, 6th ed. New York, NY: Oxford University Press; 2009.

28. Moran D. Introduction to Phenomenology. Abingdon, UK: Routledge; 2000 .

29. Husserl E. Collected Works. The Hague, The Netherlands: Nijhoff; 1980.

30. Söderhamn O. Aspects of validity and reliability in a phenomenological sense. Theoria: J Nurs Theory. 2001;10(2):12-17.

31. Arendt H. The Human Condition, 2nd ed. Chicago, IL: The University of Chicago; 1958.

32. Enkvist Å, Ekström H, Elmståhl S. Associations between functional ability and life satisfaction in the oldest old: results from the longitudinal population study. Clin Interv Aging. 2012;7:313-320.
33. Rennemark M, Lindwall M, Halling A, Berglund J. Relationships between physical activity and perceived qualities of life in old age. Results of the SNAC study. Aging Ment Health. 2009;13(1):1-8.

34. Tse M, Wan V, Ho S. Physical exercise: does it help in relieving pain and increasing mobility among older adults with chronic pain? J Clin Nurs. 2011;20(5-6):635-644.

35. Øverenget E. Hanna Arendt. Oslo, Norway: Universitetsforlaget; 2001.

36. Söderhamn U, Dale B, Söderhamn O. Narrated lived experiences of self-care and health among rural-living older persons with a strong sense of coherence. Psychol Res Behav Manag. 2011;4(1):151-158.

37. Andersson JE. Architecture for the silver generation: exploring the meaning of appropriate space for ageing in a Swedish municipality. Health Place. 2011;17(2):572-587.

38. Burton E, Mitchell L, Stride C. Good places for ageing in place: development of objective built environment measures for investigating links with older people's wellbeing. BMC Public Health. 2011; 11(1):839-852.

39. Davis M, Fox K, Hillsdon M, et al. Getting out and about in older adults: the nature of daily trips and their association with objectively assessed physical activity. Int J Behav Nutr Phys Act. 2011;8(1):116-125.

40. Burns VF, Lavoie J-P, Rose D. Revisiting the role of neighbourhood change in social exclusion and inclusion of older people. J Aging Res. 2012;2012:148287.

41. Söderhamn O, Skisland A, Herrman M. Self-care and anticipated transition into retirement and later life in a Nordic welfare context. J Multidiscip Healthc. 2011;4:273-279.

42. Söderhamn U, Landmark B, Aasgaard L, Eide H, Söderhamn O. Volunteering in dementia care - a Norwegian phenomenological study. J Multidiscip Healthc. 2012;5:61-67.

43. Ellis J. You've got a friend. Nurs Older People. 2010;22(5):9.

44. Harris AHS, Thoresen CE. Volunteering is associated with delayed mortality in older people: analysis of the longitudinal study of aging. J Health Psychol. 2005;10(6):739-752.
Clinical Interventions in Aging

\section{Publish your work in this journal}

Clinical Interventions in Aging is an international, peer-reviewed journal focusing on evidence-based reports on the value or lack thereof of treatments intended to prevent or delay the onset of maladaptive correlates of aging in human beings. This journal is indexed on PubMed Central, MedLine, the American Chemical Society's 'Chemical Abstracts Ser-

\section{Dovepress}

vice' (CAS), Scopus and the Elsevier Bibliographic databases. The manuscript management system is completely online and includes a very quick and fair peer-review system, which is all easy to use. Visit http://www.dovepress.com/testimonials.php to read real quotes from published authors. 